\title{
Erratum to: The porphyrias: pathophysiology
}

\section{Antonello Pietrangelo}

Published online: 27 March 2011

(C) SIMI 2011

\section{Erratum to: Intern Emerg Med (2010) 5(Suppl 1):S65-S71 DOI 10.1007/s11739-010-0452-z}

The article: "The porphyrias: pathophysiology" (A. Pietrangelo. Inter Emerg Med 2010; 5(Suppl 1): S65-S71) has been retracted on request of the Editor because it reproduced sections of another article: "Molecular aspects of the inherited porphyrias" (S. Sassa, A. Kappas. J Int Med 2000; 247:169-178).

Dr. Pietrangelo acknowledges full responsibility for this unfortunate situation, which he attributes to a material mistake and not to an intentional plagiarism. As a matter of fact, the Sassa and Kappas article was correctly quoted and referred to in Pietrangelo's article. Whichever was the mechanism, the result was a violation of the publishing rules and the Editor-in-Chief and the Publisher are deeply sorry for any inconvenience that this may have caused to the Editorial and Publishing staff of Journal of Internal Medicine and to the Authors of the reproduced article.

The online version of the original article can be found under doi:10.1007/s11739-010-0452-z.

\footnotetext{
A. Pietrangelo $(\square)$

$2^{\circ}$ Division of Internal Medicine,

Center for Hereditary Liver Diseases,

"Mario Coppo"' Liver Research Center,

University Hospital of Modena, Via del Pozzo 71,

41100 Modena, Italy

e-mail: antonello.pietrangelo@unimore.it
} 